\title{
Review
}

\section{KARAKTERISTIK LAHAN PESISIR DAN PENGELOLAANNYA UNTUK PERTANIAN}

Oleh: Amar Ma'ruf

Universitas Asahan

\section{KARAKTERISTIK LAHAN PESISIR}

Lahan pesisir sesuai dengan ciricirinya adalah sebagai tanah pasiran, dimana dapat dikategorikan tanah regosal. Menurut Darmawijaya (1992), tanah regosal di sepanjang pantai di beberapa tempat, diantaranya Cilacap, Parangtritis, adalah berupa bukit - bukit pasir terbentuk dari pasir - pasir pantai berasal dari abu vulkanik oleh gaya angin yang bersifat deflasi dan akumulasi. Tanah ini mempunyai ciri - ciri diantaranya:

- bertekstur kasar

- mudah diolah

- gaya menahan air rendah

- permeabilitas baik

- makin tua teksturnya makin halus dan permeabilitas makin kurang baik

Selanjutnya, menurut Sukresno (2000), tanah wilayah pantai berpasir:

- Tanah wilayah pantai berpasir bertekstur kasar, lepas-lepas dan terbuka menjadi sangat peka terhadap erosi angin.

- Hasil erosi angin berupa pengendapan material pasir menganggu dan menutup wilayah budidaya dan pemukiman.

- Butiran material pasir beragam yang terangkut oleh proses erosi pasir menyebabkan kerusakan tanaman budidaya serta mempercepat korosi barang-barang logam.

Tanah regosal umumnya mempunyai susunan hara tanaman cukup $\mathrm{P}$ dan $\mathrm{K}$ yang masih segar dan belum siap diserap oleh akar tanaman, serta kekurangan unsur N. Hasil penelitian Sutikno (1998) sifat fisik tanah pasiran di Samas Yogyakarta, yaitu bertekstur pasir, struktur lepas, kandungan bahan organik rendah dan $\mathrm{pH}$ 5,5-6,5 ukuran butiran rentan terhadap erosi. Hasil penelitian sifat fisik dan kimia tanah lahan pasiran di daerah Karangwuni, Wates, Kulon Progo dapat diutarakan sebagai berikut2): kelas tekstur pasir, berat volume 1,46 - 1,50, parositas 44,03 - 44,91\%, permeabilitas sangat cepat, bahan organik $1,34-1,37 \%, \mathrm{~N}$ total $0,07-0,11 \%$, P tersedia 42,65 - 50,32 ppm, K tersedia 0,19 $-0,23$ me/100 gram dan pH 5,91 - 6,13. Dengan demikian tanah lahan pesisir mempunyai sifat kemarginalan terhadap tekstur tanah, kemampuan menahan air, kandungan kimia dan bahan organik tanah. Namun di lahan kawasan pesisir selatan Yogyakarta menampilkan ketersedian air tanah yang cukup memadai, sehingga kedalaman air sumur mencapai tujuh meter dari permukaan tanah. Hal ini merupakan nilai tambah kondisi kawasan lahan berpasir. Disamping sistem tanah lahan kawasan pesisir yang mempunyai sifat marginal dan nilai tambah yang rendah, dan juga dari sistem atmosfernya. Di lahan pesisir mempunyai ciri 
kecepatan angin yang cukup tinggi sehingga dapat dimanfaatkan tenaganya sebagai tenaga mekanis untuk menaikkan air sumur melalui kincir angin. Kandungan material udara banyak mengandung material pasir dan bahan kimia dari laut yang kurang menguntungkan bagi kehidupan tanaman.

\section{PENGELOLAAN LAHAN}

Beberapa bentuk perbaikan lahan kawasan pesisir:

1. Teknologi perbaikan sifat fisik - kimia dan organisme tanah. Tujuan perbaikan ini adalah agar tanah pasiran dapat.
a. Terbentuk agregat, tidak lepas-lepas, mampu menahan air baik yang hilang berupa perlokasi atau evaporasi.
b. Mampu menyediakan unsur hara makro dan mikro bagi tanaman
c. Terwujudnya kekayaan mikro tanah yang dapat membantu kesuburan kimiawi dan fisika tanah.

2. Teknologi peningkatan hubungan tanah dan atmosfir

Budidaya tanaman pada umumnya diharapkan hasilnya berupa daun, biji, batang, bunga, kulit dan umbi. Masing-masing produk akan sangat tergantung fotosintesis yang memberi energi utama adalah energi matahari dari $0,4 \mu-0,7 \mu$. Masing-masing gelombang elektromagnetik akan sangat berpengaruh terhadap hasil fotosintesa. Maka diperlukan teknologi yang mampu menghasilkan produksi biomas seperti yang diharapkan. Kawasan pesisir bercirikan kecepatan angin yang cukup cepat, maka perlu teknologi pengendali energi angin dan pemanfaatan energi angin. Udara di lahan pantai mengandung anasir yang merugikan kehidupan tanaman maka diperlukan teknologi yang mampu mengurangi kerusakan tanaman akibat bencana angin dan udara. Dengan kata lain perlu Teknologi Atmosfiriq tanaman yang mendatangkan hasil guna dari ekosistem pertanian.

Untuk mengantisipasi permasalahan dilahan pasir tersebut diperlukanupaya perbaikan sifat fisika dan kimia tanah. Perbaikan yang dapat dilakukan antara lain :

\section{Penggunaan Mulsa}

Penggunaan mulsa pada permukaan tanah bertujuan untuk mengurangi kehilangan air dari tanah. Mulsa permukaan tanah dapat menggunakan lembaran plastik, jerami padi atau sisasisa tanaman lainnya. Pemasangan mulsa plastik di lahan pasir pantai berbeda dari pemasangan mulsa di lahan sawah. Pemasangan mulsa di lahan pasir dengan bentuk cekung ditengah. Bentuk cekung bertujuan agar air hujan atau penyiraman masuk ke dalam tanah. Penggunaan mulsa ini sangat penting dilahan pantai karena dapat menghemat lengas tanah sehngga kebutuhan lengas untuk tanaman terutama pada musim kemarau diharapkan dapat tercukupi. Dari hasil penelitian pemberian mulsa glerecidea dan jerami padi sebanyak 20-30 ton dapat meningkatkan hasil pada tanaman jagung di lahan pantai, selain itu pemberian mulsa berupa pangkasan tanaman ternyata juga lebih efektif sebagai mulsa dibadingkan dengan pemerian pupuk hijau (Putri, 2011). 


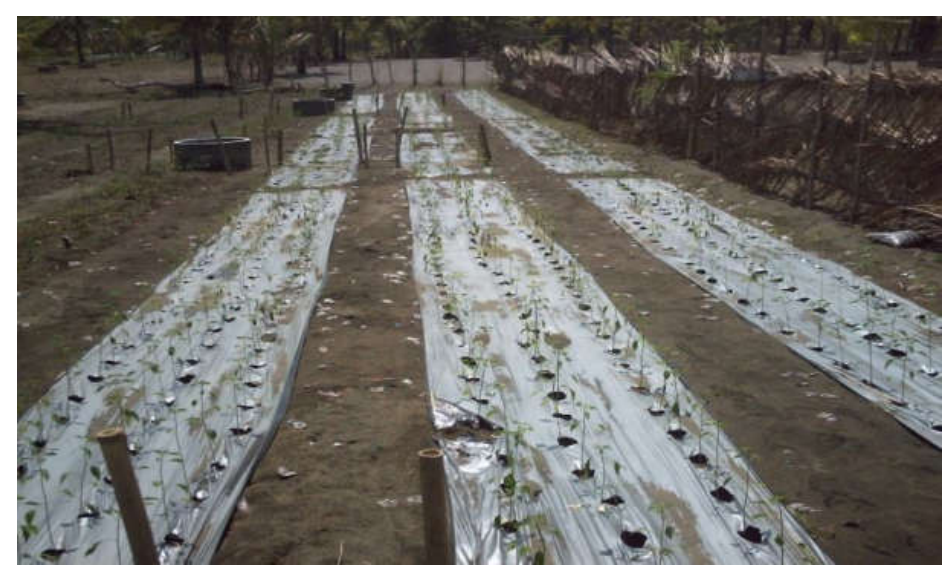

Gambar 1. Penggunaan Mulsa di Lahan Pasir Pantai

Pengaruh mulsa organik terhadap pertumbuhan dan hasil tiga varietas kacang hijau (Vigna radiata 1 . Wilczek) di lahan pasir pantai bugel, kulon progo.

Varietas Vima-1 dan Murai memiliki respons yang lebih baik dibanding varietas Lokal Wonosari pada penanaman di lahan pasir. Kacang hijau Vima-1 dan Murai mampu merespon penggunaan mulsa organik di lahan pasir pantai, dengan selisih hasil masingmasing 0,51 ton/ha dan 0,45 ton/ha dibanding tanpa mulsa. Kacang hijau Lokal Wonosari kurang merespon penggunaan mulsa organik, dengan selisih hasil sebesar 0,12 ton/ha dibanding tanpa mulsa.

\section{Pemberian bahan organik}

Bahan organik yang dapat diberikan di lahan pasir pantai dapat berupa pupuk kandang (sapi, kambing/domba dan unggas), kompos, pupuk hijau, dan blotong. Pemberin bahan organik dapat dilakukan dengan cara mencampur bahan organik ke dalam tanah atau pemberian baan organik di permukaan tanah di sekitar tanaman. Bahan organik dapat diberikan ke lahan dalam kondisi sudah matang atau mentah. Pemberian bahan organik dalam kondisi mentah bertujuan untuk mengurangi pelindian, sehingga dekomposisi bahan organik mentah akan terjadi sinkronisasi pelepasan hara dengan kebutuhan hara bagi tanaman. Kebutuhan bahan organik pada lahan pasiran lebih banyak dari lahan konvensional yaitu sekitar $15-20$ ton. Penelitian menunjukkan bahwa pemberian pupuk kandang sebanyak 20 ton dapat menekan penggunaan NPK menjadi $200 \mathrm{~kg} /$ ha (Putri, 2011). 


\section{Penggunaan bahan-bahan halus}

Penggunaan bahan halus di lahan pasir pantai dapat memanfaatkan tanah lempung, abu vulkan, endapan saluran sungai, kolam waduk. Penggunaan bahan halus bertujuan untuk meningkatkan jumlah koloid dalam tanah, khususnya penambahan fraksi lempung. Peningkatan jumlah bahan halus dalam tanah akan bermanfaat terhadap peningkatan hara dan air.

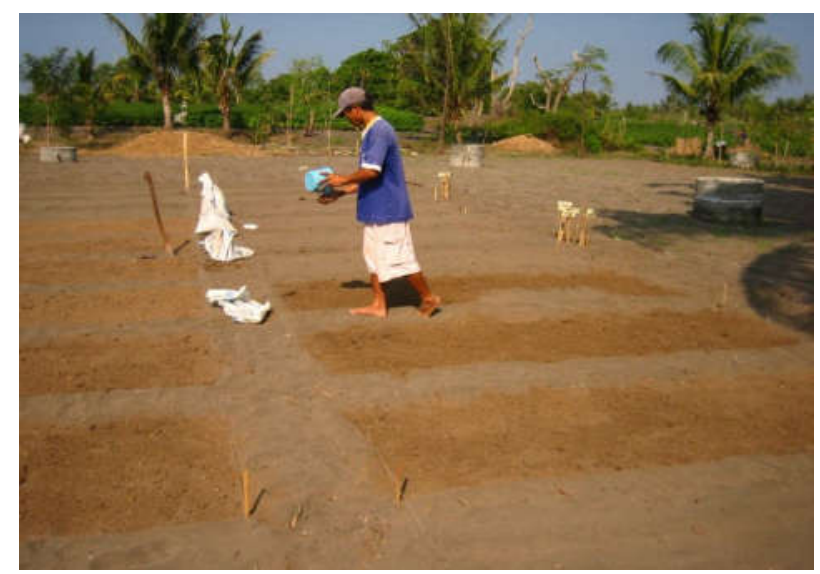

Gambar 2. Pemberian lumpur di lahan pasir pantai

\section{Penggunaan Lapisan Kedap}

Penggunaan lapisan kedap bertujuan untuk menghalagi infiltrasi air, sehingga air lebih lama tertahan dalam tanah pasir pantai. Laspisan kedap dapat memanfaatkan lembaran plastic, aspal, bitumen, lempung, pemampatan, semen. Lapisan kedap dibuat dengan cara menggali tanah terlebih dahulu kemudian lapisan dihamparkan, selanjutnya diatas lapisan kedapt diberi tanah.

\section{Penggunaan Pemecah Angin}

Penggunaan pemecah angina bertujuan untuk mengurangi kecepatan angin dalam pertanaman lahan pasir. Pemecah angina dapat dibedakan menjadi 2 macam yaitu pemecah angin sementara dan permanent. Pemecah angin sementara dapat memanfaatkan anyaman daun tebu atau kelapa, kasa nilon dan lembaran plastic. Sedangkan pemecah angin permanent dapat memanfaatkan tanaman yang berupa tumbuhan tahunan yang umurnya panjang dan dapat diatur pertumbuhannya. Jenis tumbuhan yang dapat digunakan, misalnya: kelapa, Accasia, Glerecidae, sengon, lamtoro, bunga turi, cemara laut dan pandan. Bangunan sementara dapat dibuat dari anyaman bambu, daun tebu, atau daun kelapa. Sementara itu, pematah angin yang bersifat tetap berasal dari tumbuhan tahunan yang umurnya panjang dan dapat diatur pertumbuhannya. Jenis tumbuhan yang dapat digunakan, misalnya: kelapa, Accasia, Glerecidae, sengon, lamtoro, bunga turi dan lain-lain.

\section{Penggunaan Pembenah Tanah}

Bahan pembenah tanah alami adalah emulsi aspal, lateks, skim lateks, kapur pertanian, batuan fosfat alam, blotong, dan zeolit (Dariah, 2007), tanah lempung (Grumusol dan Latosol) (Kertonegoro, 2000), lumpur sungai dan limbah karbit (Rajiman, 2010). Tujuan penggunaan bahan pembenah tanah adalah : a. Memperbaiki agregat tanah, b. Meningkatkan kapasitas tanah menahan air (water holding capacity), c. Meningkatkan kapasitas pertukaran 
kation (KPK) tanah dan d. Memperbaiki ketersediaan unsur hara tertentu. Pemanfaatan pembenah tanah harus memprioritaskan pada bahan-bahan yang murah, bersifat insitu, dan terbarukan. Pada kesempatan ini, pembenah tanah yang akan dibicarakan banyak menyangkut bahan alami. Pembenah tanah secara alami dapat diambil dari lingkungan sekitar lahan atau dari daerah lain. Pembenah tanah yang biasa digunakan di lahan pasir pantai berupa bahan berlempung dan atau bahan organik.

\section{Penggunaan sistem lorong}

Alternatif lain dalam teknologi budidaya yang dapat diterapkan untuk lahan pantai adalah sistem penanaman lorong (alley cropping). Sistem penanaman lorong merupakan sistem penanaman dengan menanam pohon-pohon kecil dan semak dalam jalur-jalur yang agak lebar dan penanaman tanaman semusim di antara jalur-jalur tersebut sehingga membentuk lorong-lorong. Tanaman lorong biasanya merupakan tanaman pupuk hijau atau legume tree. Di lahan pantai, budidaya lorong diterapkan untuk mengatasi berbagai permasalahan seperti: intensitas matahari, erosi permukaan oleh angin, dan laju evapotranspirasi. Selain itu, dapat juga berfungsi sebagai pematah angin sehingga mereduksi kecepatannya.

\section{Hidrologi dan Irigasi}

Ketersediaan air irigasi di lahan pantai yang terbatas mengakibatkan perlunya upaya untuk meningkatkan efisiensi pemanfaatan air irigasi sehingga dapat mengurangi pemborosan dalam penggunaan air irigasi. Irigasi dilahan pantai selama ini dilakukan dengan cara penyiraman dan penggunaan sumur renteng. Sedangkan untuk mengurangi kehilangan air siraman dan mempertahankan lengas, salah satu upaya yang dapat dilakukan adalah dengan penggunaan lembaran plastik yang ditanam pada jeluk $30 \mathrm{~cm}$. Hal ini dimaksudkan untuk menciptakan suatu lapisan kedap guna mencegah atau menghambat agar air irigasi yang diberikan dapat ditahan oleh lapisan tersebut sehingga efisiensi pemanfaatan air oleh tanaman dapat ditingkatkan. Dalam pengelolaan lahan pantai selain harus menggunakan berbagai teknologi untuk memanipulasi lahan, kita juga harus memperhatikan pula kelestarian lingkungan di lahan pantai, hal ini dilakukan terutama terhadap sumber daya air tawar yang sangat penting bagi pertanian lahan pantai. Jangan sampai menggunakan air tanah secara berlebihan karena dapat menyebabkan intrusi air laut ke daratan, untuk itu manajemen untuk mempertahankan kelengasan sangat penting terutama dalah hal untuk mengawetkan keberadaan sumber air tawar di pantai. Selain itu dalam pelaksanaan pertanian lahan pantai harus pula memperhatikan kehidupan sosial para warganya, jangan sampai cara-cara budidaya yang ada bertentangan dengan adat istiadat warga sekitarnya (Putri, 2011). 


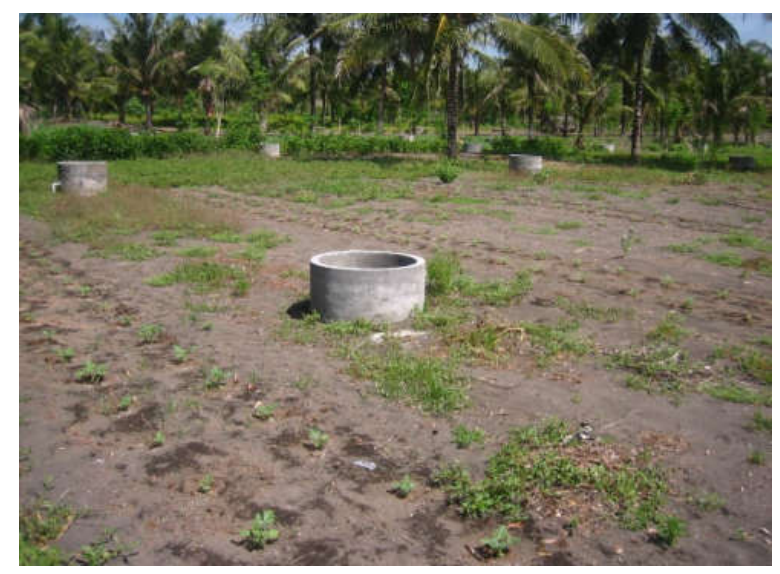

Gambar 3. Penggunaan sumur renteng untuk irigasi

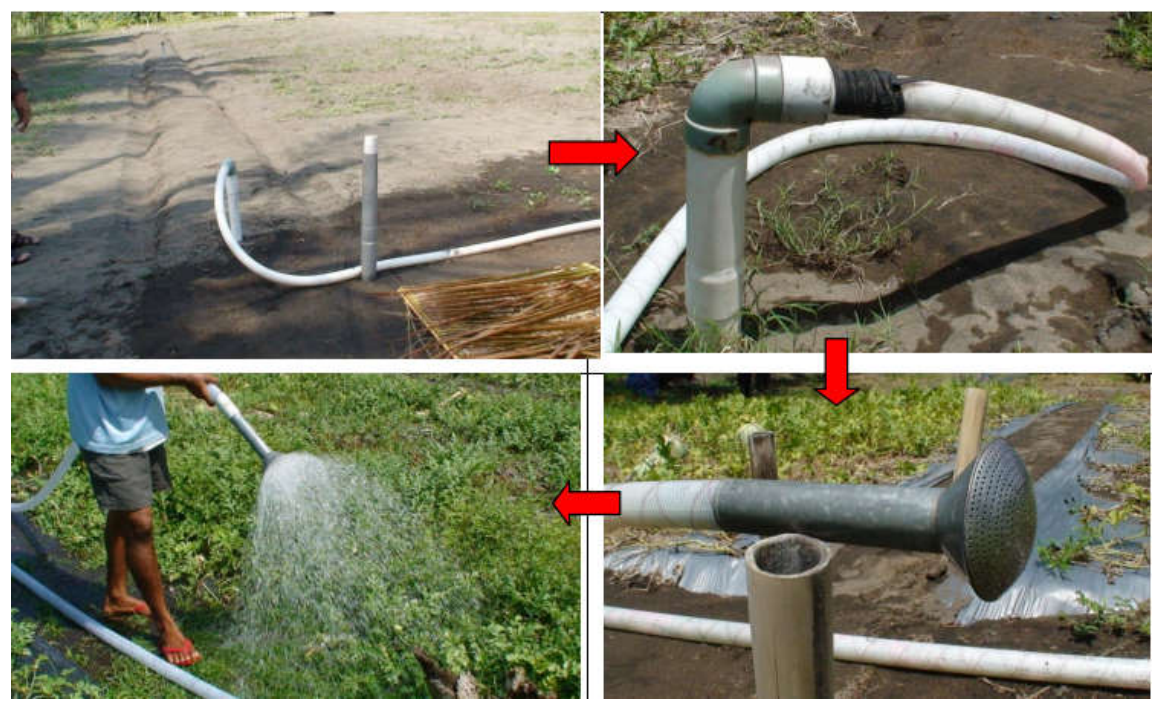

Gambar 4. Penggunaan pompa air dan selang untuk pemenuhan air.

\section{BEBERAPA KOMODITAS PADA LAHAN PASIR PANTAI \\ Buah naga}

1. Pemanfaatan Lahan Pasir Pantai Untuk Budidaya Buah Naga

Misal pada penelitian di pantai selatan. Lahan pasir pantai selatan mengandung pasir $>95 \%$, mempunyai struktur kasar, konsistensi lepas, kurang baik menahan air, permeabilitas dan drainase sangat cepat miskin kandungan hara. Oleh karena itu, penanaman buah naga di lahan pasir pantai harus ditambah tanah lempung dan pupuk kandang dengan perbandingan 1:1.

\section{Cara Membudidayakan Buah Naga di Lahan Pasir Pantai}

Kriteria bibit yang baik harus berwarna hijau kebiruan atau hijau gelap, penampilan fisik kekar dan keras, serta tampak tua. Ukuran batang 50-80 cm dengan diameter batang $8 \mathrm{~cm}$. Penanaman tiap-tiap beton sebanyak 4 bibit. Pemeliharaan setelah seminggu penanaman yaitu tanaman yang mati, busuk pada pangkal batang, tidak tumbuh atau kerusakan fisik lainnya harus segera diganti dengan setek yang baru. Pemangkasan tanaman bertujuan untuk memperoleh keseimbangan pertumbuhan dan dilakukan sedini mungkin supaya tanaman menjadi lebih teratur. Pengairan buah naga di lahan pasir pantai jangan terlalu kering harus 
segera disiram dan penyiraman jangan terlalu banyak karena kalau terendam akan terserang busuk batang. Pemupukan buah naga perlu dilakukan sebagai penyimpan air, menjaga kelembaban tanah, penghemat air penyiraman. Komposisi pupuk yang digunakan dalam budidaya buah naga adalah pupuk organik dan anorganik. Buah naga yang siap panen umunya merupakan buah yang sudah tua, kulit berwarna merah tua mengkilap. Pasca panen batang bekas buah dipotong untuk merangsang pertumbuhan tunas baru. Pemasaran buah naga untuk saat ini di pasarkan oleh petani langsung ke swalayan dan toko buah-buahan segar atau pedagang langsung menemui petani. Manfaat budidaya buah naga bisa dijadikan sebagai tanaman obat, menambah pendapatan petani, pemasukan devisa daerah dan sebagai wisata pertanian (agrowisata).

\section{Bawang merah di Pantai Samas, Yogyakarta}

Sistem penanaman menggunakan sistem bedengan. Ukuran bedengan 1 meter x 6 meter dengan tinggi $30 \mathrm{~cm}$. Pertama diawali dengan olah tanah menggunakan cangkul kemudian tanah diratakan menggunakan alat serok. Setelah rata, permukaan tanah ditaburi oleh pupuk organik sebanyak $5 \mathrm{~kg}$ per bedeng dan tanah siap ditanami bawang. Jarak tanam benih 20-25 cm dengan cara dilubangi terlebih dahulu menggunakan jari, lalu benih bawang merah dimasukkan ke dalam lubang dengan posisi akar di bawah. Tanpa menutup lubangnya, bedengan yang sudah ditanami bawang merah langsung disiram atau dilembabkan. Sistem pengairannya pun ada dua, yaitu dengan penyiraman langsung, dan menggunakan sistem aliran diantara tiap-tiap bedengan. Biasanya, petani juga menanam timun atau tanamantanaman lain secara bersamaan di sela-sela tanaman bawang merah tersebut (tumpang sari).

Pembuatan pupuk organik yang digunakan cukup mudah. Pertama, pembuatan mikroba yang terdiri dari lemen 1 ekor sapi, tetes tebu 5 liter, kapur 5 sdm, terasi 200 gr, ragi 200 gr dan kemudian disimpan di tong tertutup selama 20 hari. Setelah mikroba jadi, kotoran sapi, sekam, dan kapur (dengan perbandingan komposisi 60:20:20) dicampur dengan mikroba kemudian ditutup selama 15 hari. Nantinya, pupuk organik ini akan memicu gulma untuk tumbuh. Namun, gulma yang tumbuh tidak terlalu banyak sehingga tidak dilakukan perlakuan khusus untuk mengendalikan gulma tersebut.

\section{Budidaya sayuran}

Sayuran daun: bagian yang dipanen merupakan bagian vegetative. Nutrisi utama sayuran daun adalah nitrogen, dapat disuplai melalui pemberian pupuk urea. Perlu dilakukan penelitian mengenai dosis dan frekuensi pemupukan $\mathrm{N}$ yang tepat, untuk meningkatkan efisiensi pemupukan. Harus diperhatikan dalam pemupukan N. Tanaman Kelebihan N, daun berwarna hijau tua (gelap), penampilan kurang menarik, mudah rusak (kualitas cepat menurun), nilai jual rendah. Tanaman kekurangan $\mathrm{N}$, daun kekuningan, kandungan gizi rendah, penampilan kurang menarik, nilai jual rendah. Efisiensi pemupukan rendah (banyak nutrisi yang terbuang). Penelitian yang telah Dilakukan, Takaran Urea: $40 \mathrm{~kg} / \mathrm{ha}$ (U4), 80 $\mathrm{kg} / \mathrm{ha}$ (U8), $120 \mathrm{~kg} / \mathrm{ha}$ (U12), dan $160 \mathrm{~kg} / \mathrm{ha}$ (U16). Frekuensi pemupukan urea: 100\% saat tanam (F1), 50\% saat tanam $+50 \% 14$ hst (F2), 1/3 saat tanam $+1 / 311 \mathrm{hst}+1 / 321 \mathrm{hst}(\mathrm{F} 3), 1 / 4$ saat tanam $+1 / 47 \mathrm{hst}+1 / 414 \mathrm{hst}+1 / 421 \mathrm{hst}(\mathrm{F} 4)$. Takaran sebesar $120 \mathrm{~kg} / \mathrm{ha}$ dan $160 \mathrm{~kg} / \mathrm{ha}$ memberikan nilai tertinggi pada semua variabel yang diamati. Frekuensi pemupukan urea 3 dan 4 kali selama satu siklus hidup tanaman sayuran daun memberikan nilai tertinggi pada 
semua variabel yang diamati. (sumber: Eka Tarwaca Susila. P. Pengembangan centra produksi sayuran dan buah di lahan pantai melalui hidroponik)

\section{PUSTAKA}

Putri, Fiadini. 2011. Bertani di Lahan Pasir Pantai. BBPP Lembang.

Anonim., 2002 Aplikasi Unit Percontohan Agribisnis Terpadu di Lahan Pasirpinsi daerah istimewa Yogyakarta. Pantai. Dinas Pertanian Tanaman Pangan Propinsi DIY dengan Fakultas Pertanian UGM Yogyakarta. 118h.

Al-Omran, A.M., A.M. Falatah, A.S. Sheta and A.R.Al-Harbi. 2004. Clay Deposits for Water Management of Sandy Soils. Arid Land Research and Management 1: 171-183.

Bulmer, E.C., and D. G. Simpson. 2005. Soil Compaction and Water Content as Factors Affecting the Growth of Lodgapole Pine Seedling on Sandy Clay Loam Soil. Can J. Soil Sci. 85 : 667-679.

Dariah A. 2007. Bahan Pembenah Tanah : Prospek dan Kendala Pemanfaatannya. Sinar Tani edisi 16 Mei 2007.Jakarta.

Kertonegoro, B. D. 2001. Gumuk Pasir Pantai Di D.I. Yogyakarta : Potensi dan Pemanfaatannya untuk Pertanian Berkelanjutan. Prosiding Seminar Nasional Pemanfaatan Sumberdaya Lokal Untuk Pembangunan Pertanian Berkelanjutan. Universitas Wangsa Manggala pada tanggal 02 Oktober 2001. h46-54.

Ma'ruf, A. 2017. Agropastura Dan Pelestarian Kearifan Lokal Untuk Keberlanjutan Pertanian Di Asahan. Bernas

Ma'ruf, A. Sinaga, A. 2016. Pengaruh Pemanasan Global Terhadap Beberapa Tanaman C3 Di Indonesia. Bernas

Ma'ruf, A. Putra, E.T.S. Waluyo, S. 2016. Pengaruh Pyraclostrobin Terhadap Aktivitas Fisiologis, Produktivitas, Dan Kualitas Pucuk Teh Assamica (camellia Sinensis Var. Assamica (mast.) Kitamura) Pada Musim Kemarau. Universitas Gadjah Mada

Ma'ruf, A. Mardu, R. Andayani, N. 2014. Respon Bibit Mucuna bracteata Terhadap Intensitas Sinar Matahari. Institut Pertanian Stiper Yogyakarta

Ma'ruf, A. Zulia, C. Safruddin. 2017. Rice Estate Development As State Owned Enterprises (SOEs) To Self Supporting For Food. European Academic Research

Ma'ruf, A. 2016. Respon Beberapa Kultivar Tanaman Pangan Terhadap Salinitas. Bernas Ma'ruf, A. Zulia, C. Safruddin. 2017. Legume Cover Crop di Perkebunan Kelapa Sawit. Forum Pertanian Asahan

Ma'ruf, A. (2017). AGROSILVOPASTURA SEBAGAI SISTEM PERTANIAN TERENCANA MENUJU PERTANIAN BERKELANJUTAN. Bernas, 13(1), 81-90.

Ma'ruf, Amar., Putra, E. T. S., \& Waluyo, S. EFFECT OF PYRACLOSTROBIN CONCENTRATION ON QUALITY SHOOTS OF ASSAMICA TEA.

Ma'ruf, A. Penggunaan Legume Cover Crop (LCC) di Perkebunan Kelapa Sawit.

Sinaga, A. Ma'ruf, A. 2016. Tanggapan Hasil Pertumbuhan Tanaman Jagung Akibat Pemberian Pupuk Urea, SP-36, dan KCl. Bernas 
Oliver, Y.M. and K.R.J.Smethem. 2002. Predicting Water Balance in a Sandy Soil : Model Sensitivity to the Variability of Measured Saturated and Near Saturated Hydraulic Properties. Australian of Soil Research 43 (1) : 87-96.

Pusat Penelitian Tanah dan Agroklimat. 1994. Survei Tanah Detail di Sebagian Wilayah D.I. Yogyakarta (skala $1: 50.000$ ). Proyek LREP II Part C. Puslittanak. Bogor.

Rajiman., 2010. Pemanfaatan Bahan Pembenah Tanah Lokal dalam Upaya Peningkatan Produksi Benih bawang Merah di Lahan Pasir Pantai Kulon Progo. Disertasi. Program Pascasarjana UGM.

Syukur, A. 2005. Pengaruh Pemberian Bahan Organik Terhadap Sifat-Sifat Tanah dan Pertumbuhan Caisin di Tanah Pasir Pantai. J. Ilmu Tanah dan Lingkungan 5 (1) : 30-38. Walter A, W.K. Silk, and U. Schur. 2000. Effect of soil pH on Growth and Cation Deposition in the Root Tip of Zea mays L. Plant growth Regul 19 (1) : 65-76

Wiyanto, G. Ma'ruf, A. Puspaningrum, E, S. Panen Rupiah dari Ladang Jahe. 2014. Bhafana Publishing 